\section{Evolution of the amniote basal ganglia}

\section{Anton Reiner, Steven E. Brauth and Harvey J. Karten}

\begin{abstract}
Recent findings indicate that the basalganglia of amniotes, i. modern birds, reptiles and mammals, contain similar neuronal subpopulations, as defined by the transmitters these neurons use and their connections. These data suggest that the evolution of the basal ganglia has been much more conservative than once believed and that this region of the forebrain performs a similar motor role in birds, reptiles and mammals. The basal ganglia of birds and reptiles, however, differ from those of mammals in that they appear to have their major influence over motor functions by an output to the tectum via the pretectum. In contrast the mammalian basal ganglia are thought to have their major influence over motor functions by an output to the motor cortex via the thalamus.
\end{abstract}

Until the late 1960 s, comparative neuroanatomists believed that the telencephalon, or cerebral hemispheres, evolved in a piecemeal fashion. That is, it was thought that at each 'step' in the evolutionary progression from lower vertebrates to man the brain was expanded by the addition of a new component to the preexisting structures of the telencephalon. Thus, traditional theories of telencephalic evolution ${ }^{1.2}$ suggested that in the primordial vertebrates (presumably pre-jawed fish), the cerebral hemispheres consisted only of olfactory components. It was thought that the 'pallidal' subdivision of the basal ganglia appeared some time during the evolution of jawed fish, followed by the appearance of the 'striatal' subdivision of the basal ganglia in the amphibian lineage. In early reptiles (now extinct), two further significant developments were assumed to have occurred: (1) the 'striatum' enlarged to relatively mammalian proportions, and (2) the forerunner of neocortex appeared in the roof of the cerebral hemispheres. Further amniote evolution was thought to have followed two diverging courses, a sauropsid pattem and a mammalian pattern In the sauropsid radiation, the 'striatum' of later reptiles (including living reptiles) was presumed to have undergone further hypertrophy while the cortical primordium remained unchanged. In birds (also part of the sauropsid radiation), even further 'striatal' hypertrophy was thought to have occurred In the mammalian lineage, by contrast, the basal ganglia were assumed to have remained relatively unchanged, but the cortical primordium was thought to have undergone immense hypertrophy to become the typically mammalian neocortex that surrounds the basal ganglia. Thus, the telencephalon of birds and living reptiles was thought to be dominated by the basal ganglia, while the telencephalon of mammals was thought to be dominated by the neocortex.

Such an evolutionary scheme accorded well with the then prevailing notions about species differences in animal behavior. Birds and reptiles were thought to be limited to a repertoire of instinctive, stereotyped behaviors involving fixed motor routines in response to environmental stimuli. Since the basal ganglia were thought to be involved in the control of such stereotyped motor routines, the behavioral limitations of non-mammals were thought to have a clear morphological basis in their purportedly basal ganglia-dominated telencephala. Mammals, by contrast, because they had evolved a neocortex, were presumed to possess a broader and much more adaptable behavioral repertoire. These classical ideas about animal behavior and telencephalic evolution rested upon a number of assumptions about comparative brain organization, about basal ganglia v. cortical function and about mammalian v. non-mammalian behavioral repertoires. Research during the last twenty years by comparative neuroanatomists, neurophysiologists, ethologists and comparative psychologists has rendered a great many of these older ideas untenable. Recent data and ideas on the evolution of neocortex $x^{3.4}$ and on comparative animal behavior ${ }^{5-7}$ have been reviewed by others and will not be discussed here. The present article will review recent findings that have considerably revised our understanding of the evolution of the basal ganglia*. These findings suggest that the basal ganglia, at least among amniotes, has evolved much more conservatively than was once thought, and that the telencephala of birds and reptiles are not dominated by the basal ganglia. Somewhat surprising (and previously unrecog- nized) differences do, however, appear to exist between birds and reptiles on one hand and mammals on the other in terms of the major outflow pathway of the basal ganglia to motor areas of the brain.

\section{Striatal organization}

Older theories of basal ganglia evolution were based on studies using much more limited techniques than those currently available. In these older studies, the location and extent of the basal ganglia were determined by examination of normal cell-stained or fiber-stained brain sections. This approach, however, is unreliable since homologous structures can vary considerably in their appearance and location in different animal species. As a consequence, the dorsal boundary of the basal ganglia in birds and reptiles, although at times disputed, came to be placed at a location that gave a considerable overestimate of the true size of the sauropsid basal ganglia. Further, the 'striatal' and 'pallidal' subdivisions of the avian and reptilian basal ganglia were frequently incorrectly identified. The currently employed terms $\dagger$ for many of the subdivisions of the lateral wall of the avian telencephalon (e.g. hyperstriatum, neostriatum, paleostriatum) were devised during the early part of this century, and are a reflection of these misconceptions as to the correspondences between telencephalic regions of birds and mammals (see Fig. 1).

Revision in our understanding of comparative basal ganglia organization has come with the recent development of a variety of pathway tracing and histochemical techniques. These techniques have allowed neuroanatomists to characterize cell groups of the nervous system in terms of the chemical features and connections of their constituent neuronal populations. Thus, using acetylcholinesterase histochemistry and catecholamine

* For the purposes of the present study, the mam malian basal ganglia are considered to consist of nucleus accumbens and the caudate-putamen ("the striaturn') and the globus pallidus ('the pallidum') The basal telencephalon has not been subdivided into somatic and olfactory subdivisions, as proposed by Heimer and co-workers ${ }^{33}$, in order to simplify the comparative analysis.

$\uparrow$ The terminology for homologous brain regions differs among the various groups of birds and reptiles. For example, the region referred to as globus pallidus in turtle is called the paleostriatum primitivum in birds. In order to simplify the comparative analysis, a uniform terminology is used in this paper to identify comparable brain regions in birds, reptiles and mammals. To find the actual name by which any given avian or reptilian brain region is identified, the reader is referred to the various cited articles. 

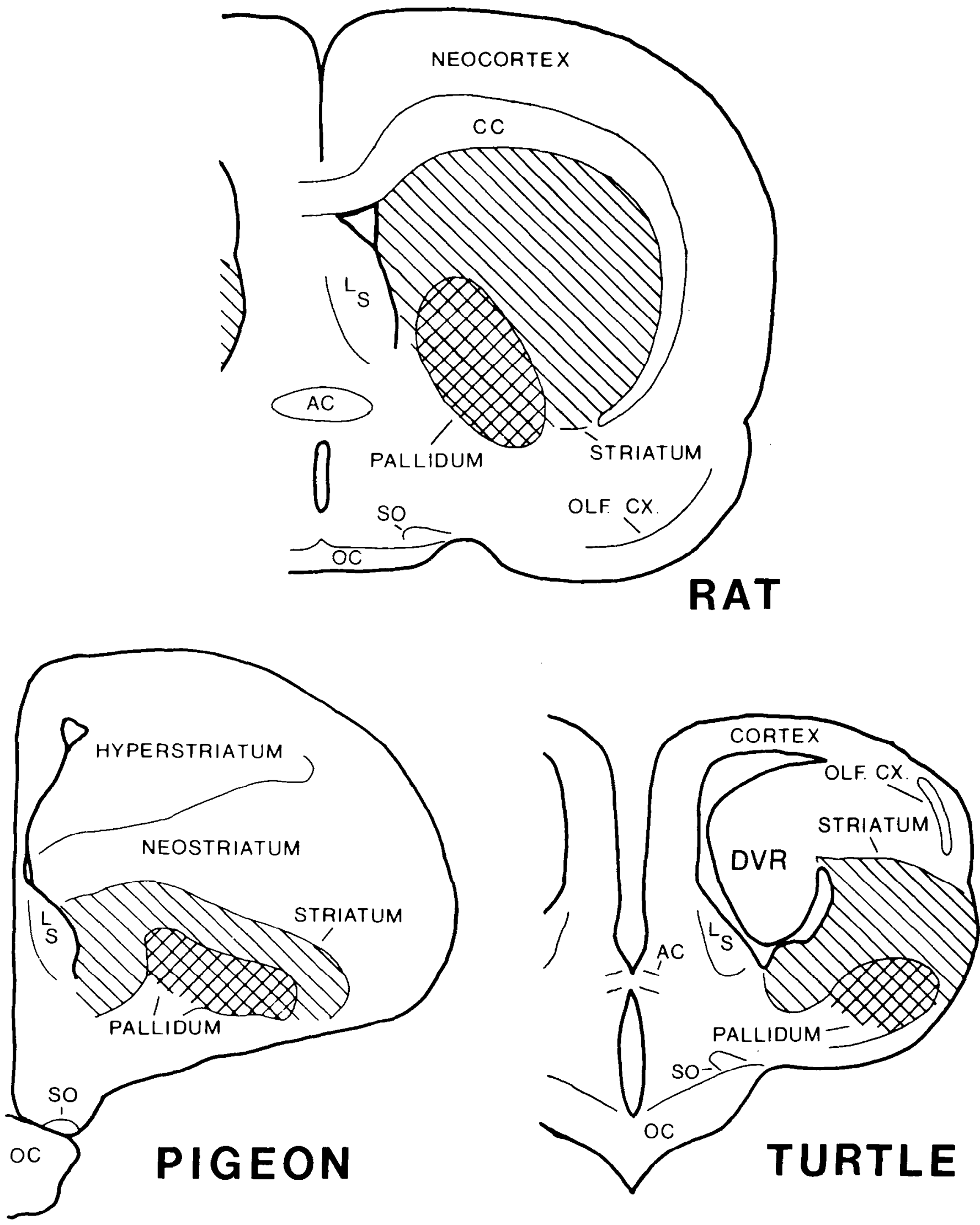

Fig. 1. Schematic line drawings of transverse sections taken at a comparable level of turtle, pigeon and rat telencephala. The drawings are not to the same scale The cross-hatched lines indicate the location of the 'pallidal' subdivision of the basal ganglia while the parallel lines indicate the 'striatal' subdivision Note that the basal ganglia comprise approximately the same proportion of the telencephalon in each species. Prior to modern histochemical studies, the dorsal ventricular ridge (DVR) of the reptilian telencephalon was considered a 'striatal' structure and the neostriatum and most of the hyperstriatum of the avian telencephalon were considered 'striatal' structures. Modem histochemical or immunohistochemical studies consistently show that the 'striatal' and 'pallidal' boundaries in birds and reptiles are as depicted above Modern studies have also shown that the neostriatum and hyperstriatum of birds and the DVR and contex of reptiles are comparable to neocortex in mammals.

Abbreviations: AC-anterior commissure; $C C$ - corpus callosum; LS-lateral septal nucleus; OC-optic chiasm; OLF. CX-olfactory cortex and SOsupraoptic nucleus. 
fluorescence histochemistry, Karten and Dubbeldam 9 showed that the so-called paleostriatum of the avian telencephalon, but not the neostriatum or hyperstriatum. was rich in acetylcholinesterase ( $\mathrm{AChE}$ )containing fibers and catecholaminergic fibers (see Fig 1). Since the mammalian 'striatum' (caudate-putamen) is characterized by distinctly higher levels of $\mathrm{AChE}$ and catecholamines than the mammalian neocortex, this result in birds suggested that the border between the avian paleostriatum and neostriatum separates 'striatum' from 'non-striatum'. The histochemical data further suggested that the two paleostriatal subfields in birds, the augmentatum and primitivum, are comparable to the mammalian striatum and pallidum, respectively. The augmentatum is the region that contains high $\mathrm{AChE}$ and catecholamine levels, while the primitivum contains low levels of both (as is typical of the mammalian pallidum). These findings in birds were corroborated by Parent and his co-workers ${ }^{10}$ and extended by Parent and several others to reptiles ${ }^{10-12}$. The findings in reptiles were essentially similar to those in birds. The ventrolateral telencephalic wall contains both a 'striatal' cell field rich in both $\mathrm{AChE}$ and catecholamines, and a 'pallidal' cell field poor in both. The dorsal border of the reptilian 'striatum' was also found to be less dorsal than was once believed by many. In mammals, the striatal AChE appears to reflect the presence of intrinsic striatal cholinergic neurons. It seems likely that the same is true in birds and reptiles. The striatal catecholamine in mammals is largely dopamine, and is contained in the terminals of striatal afferent fibers originating from the substantia nigra $a^{13}$. Recent studies in a variety of birds and reptiles have shown that a dopaminergic tegmental 'nigral' cell group is the source of most of the catecholamine-rich terminals in the striatum ${ }^{10,11.14}$. The 'striatum' of birds, reptiles and mammals is also known to receive adrenergic and serotonergic innervation from the isthmic hindbrain 10,1114 .

Recent pathway tracing studies have shown that the 'striatum' of birds and reptiles has additional connections that are characteristic of the mammalian striatum (Fig. 2). In mammals, the neocortical input to the striatum largely arises from neurons that do not project outside the telencephalon ${ }^{15.16}$. The major intratelencephalic input to the avian and reptilian striatum appears to be from cortical or corticalequivalent regions overlying the striatum (Refs 11 and 14, and Reiner, A, unpublished observations). In birds, this telencephalic field projecting to the striatum also appears not to project outside the telencephalon. In birds, reptiles and

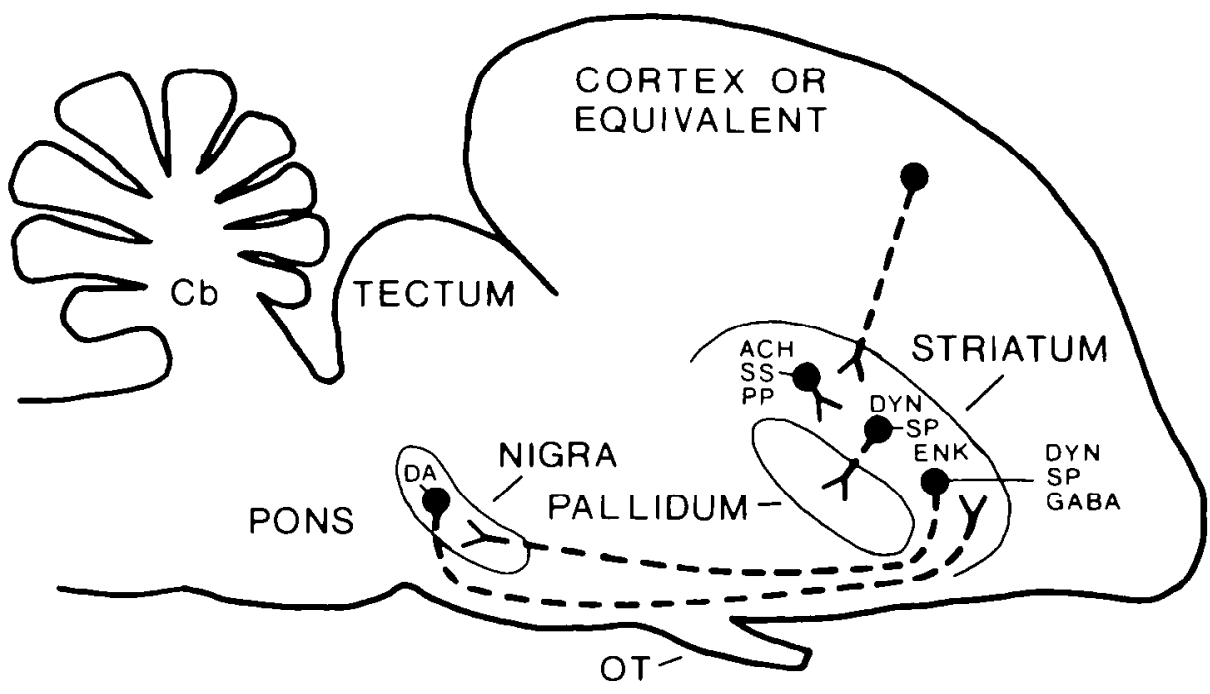

Fig 2. Sagittal view of a schematized amniote brain showing the major cell types and connections of the basal ganglia that are common to all amniotes studied. The 'striatal' subdivision of the basal ganglia receives an input from neocortical neurons (in mammals) or from neurons found in the field homologue of neocortex (in birds and reptiles). Three types of neurons are found in the striatum, intrinsic neurons, striatopallidal projection neurons and striatonigral projection neurons. These neuron types may not always be mutually exclusive, eg. striatopallidal neurons may also project to the nigra. Three transmitter specific intrinsic neuron types have been identified in the amniote striatum, acetylcholine-containing $(A C h)$ neurons, somatostatin-containing (SS) neurons and pancreatic polypeptide-like immunoreactivity containing (PP) neurons. Among striatopallidal neurons, separate populations of substance P-containing $(S P)$, enkephalin-containing ( $E N K)$ and dynorphin-containing ( $D Y N)$ neurons appear to project from the striatum to the pallidum in amniotes. Some substance P-containing and dynorphin-containing 'striatal' neurons project to the nigral cell group of the midbrain. It is presently unknown if the same individual peptidergic striatal neurons project to both the pallidum and to the nigra. In birds and mammals GABAergic striatonigral projection neurons have also been demonstrated Neurons of the nigra contain dopamine $(D A)$ and project back to the striatum. Abbreviations: $C b$-cerebellum.

mammals, the 'striatum' has a major efferent projection to the 'pallidum'. Recent immunohistochemical studies have provided clues as to the transmitters used by these striatopallidal projection neurons. Substance $\mathrm{P}(\mathrm{SP})$-containing terminals in the 'pallidum' apparently arise from striatal neurons that contain this neuropeptide ${ }^{17-19}$. Similarly, enkephalin-containing terminals in the 'pallidum' also apparently arise from striatal neurons that contain this peptide ${ }^{20-23}$. This appears to be true in all amniotes. Further, other neuropeptides, such as somatostatin and a pancreatic polypeptide-like substance, have been identified in striatal neurons in all classes of amniotes (Refs 8, 24 and 25, and Reiner, A, unpublished observations). In mammals, the projections of these somatostatinergic and pancreatic polypeptidecontaining neurons are thought to be intrinsic to the striatum. A large number of the SP-positive striatal neurons give rise to an additional major SP-containing striatal projection that terminates outside the telencephalon in the dopaminergic 'nigral' cell group in birds, reptiles and mammals ${ }^{17,18,26.27}$. In all amniotes studied, the SP-positive neurons that give rise to this projection appear to have their highest concentration in medial striatal regions.
In birds, the SP data have brought about the recognition that the avian 'striatum' actually comprises two cell groups previously thought to be distinct, the paleostriatum augmentatum and the so-called lobus parolfactorius. Additional transmitter-specific striatonigral projection neurons (namely GABAergic and dynorphinergic) also appear to be common to both the mammalian and the sauropsid striata $^{22,23,28-30}$

Thus, the histochemical and pathway tracing data of the last ten years indicate that the striatum consists of many of the same neuronal constituents in birds, reptiles and mammals (Fig. 2). The seeming ubiquity of these neuronal constituents among extant amniotes leads us to suggest that these constituents were also present in the reptilian common ancestors of living amniotes. Some of these striatal features may also have been present in the ancestral amphibians since the frog 'striatum' contains both SP-positive and enkephalin-positive neurons and receives a catecholaminergic input from the midbrain tegmentum (Refs 10 and 31 , and Reiner, A, unpublished observations). Although the precise ancestry of the neuronal components of the amniote striatum is not entirely clear at present, the recent 
findings emphasize the relative evolutionary stability of striatal organization among amniotes. Although some differences do appear to exist (chiefly in terms of the topographic distribution of cell types), we believe the many similarities render untenable the more classic theories that assumed profound differences in striatal organization.

The function of the sauropsid 'striatum' is presently unclear. Few data are avair able on the microcircuitry or neurophysiology of the constituent neuronal populations of the sauropsid 'striatum', although the firing patterns of striatal neurons are apparently similar in birds and mammals (Brauth, S. E., unpublished observations). Several studies indicate that experimental manipulations of the striatonigral system (either by pharmacological means or by surgical intervention) produce similar beha vioral effects in birds and mammals ${ }^{32-35}$. The overall neuroanatomical and histochemical similarities and the available physiological data lead us to suggest that the 'striatum' plays the same kind of role in motor functions in sauropsids as in mammals. In mammals, the striatum is thought to play a role in the initiation and maintenance of motor routines ${ }^{36}$. We suggest that there is no reason to assume that the sauropsid striatum serves a different function, e.g as the neural locus of the control circuitry for stereotyped speciesspecific behavior routines $\ddagger$. In mammals, the striatum effects its influence on motor functions (in large part) via a striatopallido-thalamo-cortical pathway. Does the sauropsid striatum influence motor functions via a similar pathway?

\section{Pallidal organization}

Although the mammalian basal ganglia may influence motor functions via the inputs of striato-nigral circuitry into the superior colliculus and the tegmental locomotor area (cuneiform region), the mammalian basal ganglia are thought to have their greatest influence on motor function via the input of pallido-thalamic circuitry into agranular and granular frontal cortex $x^{37}$. In monkey, the globus pallidus (pars interna) projects to the ventral lateral and ventral anterior nuclei of the thalamic ventral tier ${ }^{37}$. These nuclei project, respectively, to motor and premotor cortices ${ }^{38}$. The lateral deep cerebellar nucleus also projects to the ventral lateral nucleus(VL). Pallidal and cerebellar inputs terminate in different portions of the VL. In birds, the

$¥$ In his theory of the triune brain and its evolution, MacLean ${ }^{53}$ has been a recent proponent of the idea that the basal ganglia (or the R-complex in MacLean's terminology) dominate the cerebral hemispheres in reptiles and are involved in the control of ritualized species-specific behaviors. 'pallidal' subdivision of the basal ganglia has only meager input to the dorsal thala mus $^{39}$. This input terminates in the dorsointermediate posterior nucleus (DIP). The caudal portions of DIP also receive a slight input from the lateral deep cerebellar nucleus. Thus, in terms of afferenta tion, DIP appears similar to the monkey VL. Unlike the VL, however, DIP does not project to a telencephalic motor cortex (if such a region even exists in birds). Instead, DIP projects to a restricted field within the neostriatum intermediale (NI) of the telencephalon. This field within NI projects to yet another cell field in the lateral portion of the cerebral hemispheres, which in turn projects to a motor output cell field within the avian telencephalon termed the archistriatum ${ }^{40}$. Nonetheless, the pallido-DIP pathway of birds is meager (in terms of the number of fibers) compared to the mammalian pallido-VL pathway. In reptiles, no clearcut equivalent of either a mammalian telencephalic motor cortex, a mammatian pallido-VL pathway or an avian pallido-DIP pathway has been
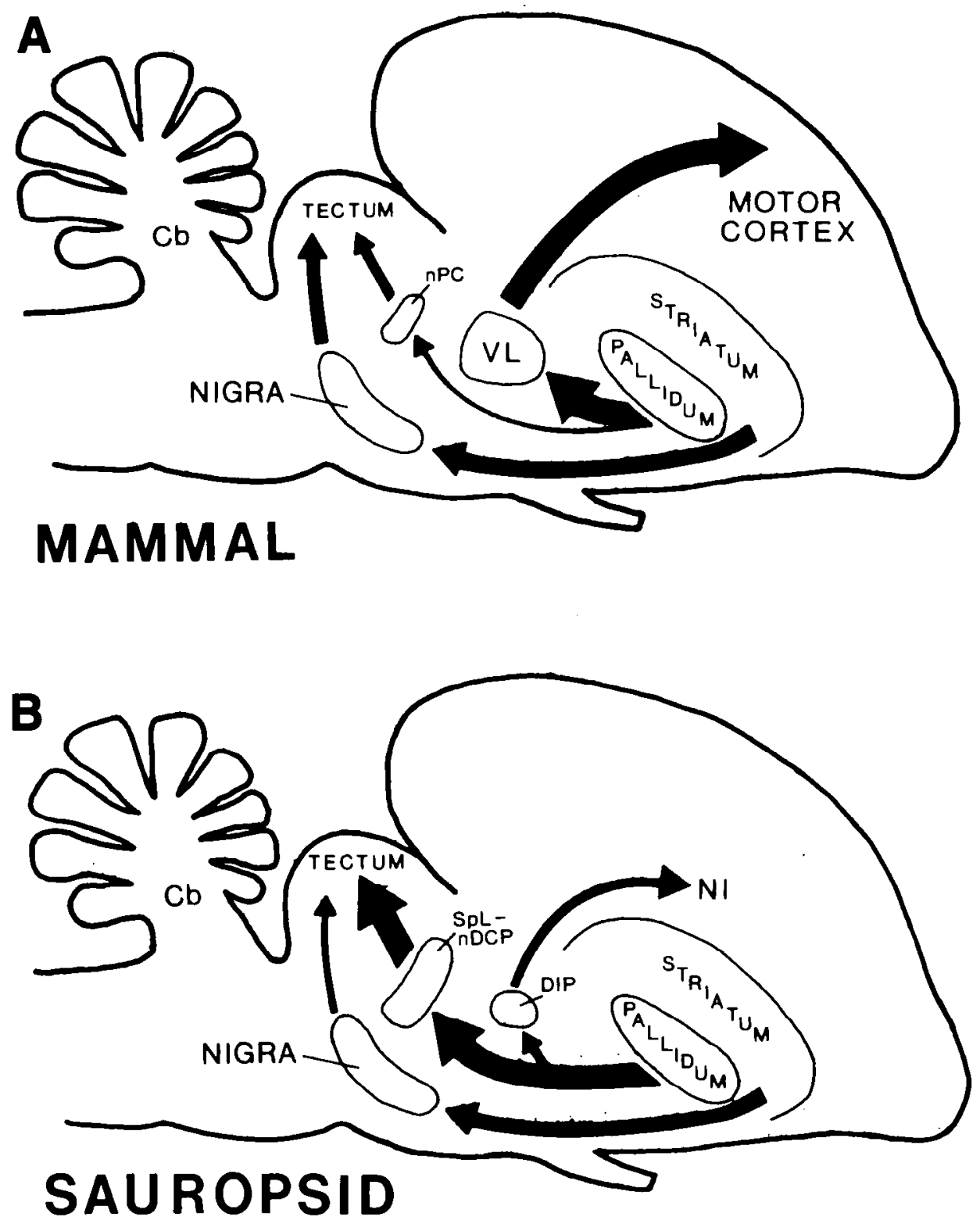

Fig. 3. Schematic sagittal sections illustrating the various outlow pathways of the basal ganglia to motor areas in mammals (A) and sauropsids (B). The thickness of each arrow indicates the relative size of that projection. In mammals, the major motor outflow route of the basal ganglia is the pallido-ventrolateral thalamic (VL)-motor cortex pathway. By contrast, a pallido-thalamo-telencephalic pathway has not been identified in reptiles and is meager in pigeons. In pigeons this pathway projects via the dorsointermediate nucleus of the thalamus (DIP) to the neostriatum intermediale (ND). It is presently unclear whether the pallido-thalamo-telencephalic pathway of binds is homologous or homoplastic to that of mammals. The major outflow of the sauropsid basal ganglia to motor areas appears to be the pallido-SpL/nDCP-tectal pathway. A similar pathway appears to be present in mammals, though the pretectal component of this pathway (the nucleus of the posterior commissure, $n C P$ ) receives only sparse pallidal input. The mammalian basal ganglia do, however, have a major input to the tectum via a striato-nigro-tectal pathway. Although striato-nigral projections are well developed in sauropsids, nigro-iectal projections are less prominent than in mammals. 
demonstrated. Thus, the available data indicate that the striato-pallidal system in birds and reptiles does not have a major influence on motor functions via a thalamotelencephalic circuit Birds and reptiles do, however, have a welt-developed pallidal projection system. By what circuitry, if any, does the well-developed striatopallidal system of birds and reptiles influt ence motor functions?

In their study of pallidal projections in birds, Karten and Dubbeldam 9 originally noted and puzzled over a massive projeotion from the avian 'pallidum' to a cell group at the mesodiencephalic junction termed the nucleus spiriformis lateralis $(\mathrm{SpL})$. A similar pallidal projection target was subsequently recognized in reptiles and termed the dorsal nucleus of the posterior commissure ( $\mathrm{nDCP})^{11,41,42}$. Atthough the function or identity of this cell group was originally unclear, recent studies suggest that $\mathrm{SpL} / \mathrm{nDCP}$ may represent the major projection target by which the sauropsid basal ganglia influence motor functions. A number of pieces of data point to this conclusion. First, SpL has been shown to receive inputs from only a limited number of sources ${ }^{43}$. The pallidal input to $\mathrm{SpL}$ is the most massive by far. In addition, SpL receives lesser inputs from two pallidal projection targets, one of them the 'nigral' cell group (this input is from nondopaminergic neurons of the nigra). The reptilian $\mathrm{nDCP}$ also appears to receive inputs from a limited number of sources, though this has been explored less fully than in birds. Both the avian $\mathrm{SpL}$ and the reptilian $\mathrm{nDCP}$ project only to the tectum (see Fig. 3). In birds and reptiles, the $\mathrm{SpL} / \mathrm{nDCP}$ input terminates in those tectal layers (the deep layers) that give rise to the efferent projections of the tectum, including the descending projections to reticulospinal projection neurons of the hindbrain ${ }^{44}$. On this basis we have proposed that this input to the tectum may modulate the activity of tectal neurons that have output to brainstem motor structures ${ }^{43}$. Bugbee ${ }^{45}$ has shown that bilateral lesions of $\mathrm{SpL}$ in pigeons result in severe impairments in the initiation and execution of tasks involving motor responses to objects moving in the birds' visual space. Birds with bilateral SpL lesions are not, however, obviously impaired in any gross sensory or motor capabilities. The visuomotor impairments in tracking behavior following $\mathrm{SpL}$ lesions are reminiscent of the impairments in tracking behavior observed in monkeys with pallidal lesions and in Parkinsonian patients ${ }^{45}$. Bugbee ${ }^{45}$ has suggested that $\mathrm{SpL}$ may serve to relay information regarding ongoing or impend- ing body movements from the basal ganglia to the tectum to co-ordinate body position with object location in visual space.

The pallido-SpL/nDCP-tectal pathway may, thus, have the same type of influences on motor functions as the pallidoVL-motor cortex pathway of mammals. The precise types of movement influenced, however, may differ as a function of the differences in projections of the tectal $v$. cortical neurons. The motor cortex in mammals is largely thought to control fine and complex movements of the muscles of the extremities ${ }^{38}$. It seems unlikely that the tectum of sauropsids controls such movements. It seems more likely that the tectum is involved in head movements (such as pecking) and general orientation and approach movements. The absence of a cerebellar input to the $\mathrm{SpL} / \mathrm{nDCP}$ tectal system may also distinguish it functionally from the VL-motor cortex system. Further, although VL and motor cortex are reciprocally connected, this is not true of $\mathrm{SpL} / \mathrm{nDCP}$ and tectum ${ }^{38}$.

Using immunohistochemical techniques, we have found an additional distinctive feature of the sauropsid $\mathrm{SpL} / \mathrm{nDCP}$. every neuron of this nucleus contains large amounts of an enkephalin-like substance ${ }^{46}$. Using enkephalin immunohistochemistry we have found that neurons of $\mathrm{SpL} / \mathrm{nDCP}$ contain enkephalin in turtles, lizards, crocodilians, snakes, chickens and pigeons ${ }^{47}$. Further, the tectal projection of SpL/nDCP appears to be enkepha linergic (Fig. 3). Enkephalinergic fibers and terminals are found in the tectal layers to which $\mathrm{SpL} / \mathrm{nDCP}$ projects. In birds, we have shown that lesions of $\mathrm{SpL}$ eliminate the enkephalinergic fibers from these layers ${ }^{46}$. Since opioid receptors have been found in the avian tectum ${ }^{48}$, it seems likely that enkephalin plays a neuroactive role at the synapses between $\mathrm{SpL}$ axon terminals and tectal neurons. Based on the actions of enkephalin in other systems, SpL presumably exerts inhibitory influences on tectal neurons. High levels of opioid receptors are also found in mammalian motor cortex 4 , but the source of the opioid peptidergic input(s) to motor cortex is presently uncertain.

\section{Evolution of sauropsid-mammal pallidal differences}

The foregoing considerations raise the question as to how or why sauropsids and mammals have evolved such seemingly disparate pallidal outflow pathways while retaining the same basic striatal pathways. Do mammals possess anything comparable to the sauropsid pallido-SpL/nDCPtectal pathway? Kuhlenbeck ${ }^{50}$ classified $\mathrm{SpL} / \mathrm{nDCP}$ as a pretectal cell group and suggested that $\mathrm{SpL} / \mathrm{nDCP}$ was one of a group of pretectal nuclei in sauropsids that are collectively comparable to the nucleus of the posterior commissure (nCP) of mammals. Kuhlenbeck noted that individual cell groups were much less readily identifiable within $\mathrm{nCP}$ than within the comparable cell field of sauropsids. Consistent with Kuhlenbeck's suggestion, the mammalian $\mathrm{nCP}$ has been shown to receive a slight pallidal input and project heavily to the tectum ${ }^{41}$. We have not, however, been able to detect enkephalin in any neurons of $\mathrm{nCP}$ in rats, rabbits or cats (Reiner, A. and Kavten, H. J. unpublished observations). On this basis, we would suggest that mammals do possess a correspondent of $\mathrm{SpL} / \mathrm{nDCP}$, but one that is relatively undifferentiated cytoarchitectionically and histochemically. Based on the findings in both sauropsids and mammals, we believe that the ancestral reptiles also possessed an $\mathrm{SpL} / \mathrm{nDCP}$ tectal system. Consistent with this sug gestion, extant amphibians have been reported to possess a basal ganglia$\mathrm{SpL} / \mathrm{nDCP}$-tectal circuit ${ }^{51}$. We hypothesize that the $\mathrm{SpL} / \mathrm{nDCP}$ system was well developed in ancestral reptiles and was greatly de-cmphasized in the line of evolution leading to modern mammals. Ancestral mammals are thought to have been nocturnal, this could have resulted in a decreased reliance on the visual system ${ }^{54}$. Such a stage in mammalian evolution would theoretically lead to a reduction in the central visual pathways, including the pathways subserving visual-basal ganglia efferent mechanisms. In the context of this hypothesis, it would be of interest to study nocturnal sauropsids to determine if the $\mathrm{SpL} / \mathrm{nDCP}$ system is reduced in these species. Significantly, snakes, which are thought to have passed through a burrowing stage during their evolution from lizards (which would theoretically also de emphasize visuat-basal ganglia mechanisms) ${ }^{52}$, possess an $\mathrm{nDCP}$ system that is anatomically and histochemically less distinct than that in crocodilians, turtles and lizards (Reiner, A, unpublished observations). In ancestral nocturnal mammals, the de-emphasis of visual-basal ganglia mechanisms may have been attended by a second event, the simultaneous development of neocortex in the telencephalon and an increased reliance on somesthesis. This second event may have led to an emphasis on functions mediated by thalamic-sensorimotor cortex and a consequent hypertrophy of the pathways related to somatosensory/somatomotor-basal ganglia efferent mechanisms. Whether the VLmotor context circuit had antecedents in 
ancestral reptiles or whether the circuit is entirely a mammalian adaptation is presently unclear. A motor cortex has not been unequivocally identified in living reptiles. Many mammals have retumed (presumably secondarily) to diurnal life styles. This, however, has not led to a reemphasis of the SpL/nDCP-tectal circuit. Instead, a striato-nigro-collicular circuit (which is present but poorly developed in reptiles and birds) appears to have elaborated to mediate visual-basal ganglia interactions ${ }^{41}$. The differences between mammals and sauropsids in terms of the outflow pathways of the basal ganglia to motor structures is summarized in Fig. 3.

\section{Summary}

Older theories of basal ganglia evolution proposed major differences between living birds and reptiles as compared to mammals in the extent and location of the basal ganglia, particularly the striatal subdivision. In contrast, our recent data indicate that the striata of birds, reptiles and mammals are comparable in location, extent, inputs, outputs and transmitterspecific neuronal constituents. These similarities presumably reflect the inheritance of these features from the common reptilian ancestors. How many of these features may have been present in the amphibians ancestral to stem reptiles is unclear since we do not have enough data on living amphibians. Sauropsids and mammals, however, appear to have undergone a divergence in the major outflow target of the 'pallidum'. In mammals, the pallidum influences the functions of motor cortex via a thalamic relay. In sauropsids, the pallidum apparently exerts its major effects on motor functions by influencing the tectum via a pretectal relay. The precise functional implications of this divergence are presently unclear but potentially highly intriguing Overall, the recent data indicate that the evolution of the basal ganglia among amniotes has been much more highly conservative than once believed; and thus, this opens the possibility that birds and reptiles may be highly valuable as subjects for study of basal ganglia structure and function.

\section{Reading list}

1 Ariens-Kappers, K. U., Huber, G.C. and Crosby, E.C. (1936) The Comparative Anatomy of the Nervous System of Vertebrates, Including Man, Hafner, NY

2 Herrick, C. J. (1948) in The Brain of the Tiger Salamander, The University of Chicago Press, Chicago

3 Nauta, W. J. H. and Karten, H. J. (1970) in The Neurosciences Second Study Program (Schmitt, F. O., ed), pp. 7-26, Rockefeller Univ. Press, New York

4 Northcutt, R. G. (1981) Annu. Rev. Neurosci 4, 301-350
5 Hodos, W. (1970) in The Neurosciences Second Study Program (Schmitt, F. O., ed), pp. 26-39, Rockefeller Univ. Press, New York

6 Mackintosh, N. J. (1974) in The Psychology of Animal Learning, Academic Press, New York

7 MacPhail, E. M. (1982) in Brain and Intelligence in Vertebrates, Clarendon Press, Oxford

8 Bear, $M$ and Ebner, F. F. (1983) Neumoscience 9,297-307

9 Karten, H. J. and Dubbeldam, J. L (1973) $J$. Comp. Neurol 148, 61-89

10 Parent, A. (1979) in Biology of the Reptilia Volume 10. Neurobiology B. (Gans, C., Northcutt, R G. and Ulinski, P., eds), pp. 247-285, Academic Press, NY

11 Brauth, S. E. and Kitt, C. A. (1980) J. Comp. Neurol 189, 437-465

12 Parent, A and Olivier, A. (1970) J. Himforsch $12,73-81$

13 Fallon, J. H. and Moore, R. Y. (1978) J. Comp. Neurol 180, 545-579

14 Brauth, S. E., Ferguson, J. L and Kitt, C. A. (1978) Brain Res. 147, 205-221

15 Jones, E. G., Coulter, J. D., Burton, H. and Porter, R (1977) J. Comp. Neurol 173, 53-80.

16 Kitai, S. (1980) in Handbook of Physiology The Nervous System II pp. 997-1015. American Physiol. Soc., Washington, DC

17 Brauth, S. E., Reiner, A. Kitt, C. A and Karten, H. J. (1983) J. Comp. Neurol 219 , 305-327

18 Reiner, A, Karten, H. J. and Solina, A. R. (1983) Neuroscience 9, 61-85

19 Staines, W. A., Nagy, J. L, Vincent, S. R. and Fibiger, H. C. (1980) Brain Res. 194, 391-402

20 Brauth. S. E. (1984) Neuroscience 11, 345-358

21 Correa, F. M. A., Innis, R. B., Hester, L D. and Snyder, S. H. (1981) Neurosci Lett. 25, 63-68

22 Reiner, A, Davis, B. M. Brecha, N. C. and Karten, H. J. (1984) J. Comp. Neurol (in press)

23 Reiner, A. (1983) Soc. Neurosci Abstr. 9, 439

24 Takatsuki, K., Shiosaka, S., Inagaki, S., Sakan aka, M, Takagi, H., Senba, E., Matsuzaki, T. and Tohyama, M (1981) J. Comp Neurol 202, 103-113

25 Vincent, S. P. and Johansson, O. (1983) J. Comp. Neurol 217, 264-270

26 Jessell, T. M., Emson, P. C., Paxinos, G. and Cuello, A. C. (1978) Brain Res $152,487-498$

27 Kith C. A and Brauth S. E. (1981) Neuroscience 6, 1551-1566

28 Dray, A. (1979) Neuroscience 4, 1407-1439

29 Hall, K. Brauth, S. E. and Kitt, C. A. (1984) Brain Res. (in press)

30 Vincent, S., Holfelt, T., Christensson, I and Terenius, L (1982) Eur. J. Pharmacol 85, 251-252

31 Inagaki, S., Senba, E., Shiosaka, S., Takagi, H, Kawai, Y., Takatsuki, K., Sanaka, M., Matsuzaki, T. and Tohyama, M. (1981) J. Comp. Neurol 210, 243-254

32 Goodman, L, Zackny, J., Osman, A, Azzaro, A. and Donovan, C. (1982) Physiol Behav. 29. $1045-1050$
33 Rieke, G. K. (1981) Physiol Behav. 26, 379 384

34 Rieke, G. K. (1982) Physiol Behav. 28, 775763

35 Sanberg, P. R. and Mark, R. F. (1983) Neuropharmacology 22, 253-257

36 Penney, J. B. and Young. A. B. (1983) Annu Rev. Neurosci 6, 73-94

37 Carpenter, M. B. (1980) in Handbook of Phys iology-The Nervous System II, pp. 997-1015, American Physiol. Soc., Washington, DC

38 Wise, S. P. and Evarts. E. V. (1981) Trends Neurosci 4, 297-300

39 Kitt, C. A. and Brauth, S. E. (1982) Neuroscience 7, 2735-2751

40 Ritchie, T. C. and Cohen, D. H. (1977) Soc. Neurosci Abstr. 3, 94

41 Reiner, A, Brauth S. E., Kith, C. A and Karten, H. J. (1980) J. Comp. Neurol 193 , 565-589

42 ten Donkelaar, H. J. and de Boer-van Huizan $R$ (1981) Neuroscience 6, 1567-1590

43 Reiner, A., Brecha, N. C. and Karten, H. J (1982) J. Comp. Neurol 208, 16-36

44 Reiner, A. and Karten, H. J. (1982) J. Comp. Neurol 204, 165-187

45 Bugbee, N. (1979) The Effect of Bilateral Lesions in the Nucleus Spiriformis lateralis on Visually Guided Behavior in the Pigeon, Ph.D. Thesis, University of Maryland, Md

46 Reiner, A., Karten, H. J. and Brecha, N. C. (1982) J. Comp. Neurol 208. 37-53

47 Brauth, S. E. and Reiner, A. (1982) Soc Neurosci Abstr. 8, 766

48 Felix, D., Henke, H. and Frangi. U. (1979) Brain Res 175, 145-149

49 Lewis, M E., Pert, A., Pert, C. B. and Herkenham, M. (1983) J. Comp. Neurol 216, 339 358

50 Kuhlenbeck, H. (1937) J. Comp. Neurol 71 , 25-75

51 Wilczynski, W. and Northcutt, R. G. (1983) J. Comp. Neurol 214, 333-343

52 Romer, A. S. (1971) in The Vertebrate Ston University of Chicago Press, Chicago

53 Heimer, L, Switzer, R D. and Van Hoesen, G. W. (1982) Trends NeuroSci 5, 83-87

54 Jerison, H. J. (1973) in Evolution of the Brain and Intelligence, Academic Press, New York

55 MacLean, P. D. (1978) in Behavior and Neur ology of Lizands (Greenberg, N. and MacLean, P. D., eds), pp. 1-10, DHEW Washington DC

Anton Reiner is at the Department of Anatomy and Cell Biology, the University of Michigan Ann Arbor, MI 48109, USA.

Steven E Brauth is at the Department of Psychology the University of Maryland, College Park, Md 20742, USA.

Harvey J. Karten is at the Department of Neuro biology and Behavior, SUNY at Stony Brook Stony Brook, NY 11794. USA

Centrefolds from Trends in NeuroSciences
Copies of the coloured diagrams published in Trends in NeuroSciences can be bought separately from the rest of the journal. The
diagrams. in colour on single sheets $30 \times 40 \mathrm{~cm}$ are available in multiples of 5 copies.
The price per 5 copies is $53.00 /$ US56.50. including postage and packing Large orders. 100 copies or more in total. are available at
$30 \%$ discount
Please order quoting:
Ref Na. 51: Basic principles of genomic and complementary DNA cloning (April 1983)
Ref. No. 52: Determination of preprohormone structure using recombinant techniques (September 1983)
Ref. No. 53: The neuronal cell lineage of a nematode (June 1984)
Send your arder with payment to:
Trends in Neurs Sciences (Centre-page Diagrams). Elsevier Publications (Cambridge).
68 Hills Road. Cambridge CB2 I LA. UK.

